\title{
Interactive Teaching in Higher Education for Effective Knowledge Dissemination and Improved Student Participation
}

\author{
Atmaram P. Pawar ${ }^{1, *}$, Vividha V. Dhapte-Pawar ${ }^{1}$, Vinod L. Gaikwad ${ }^{2}$ \\ 1'Department of Pharmaceutics, Poona College of Pharmacy, Bharati Vidyapeeth (Deemed to be University), Pune, Maharashtra, INDIA. \\ ${ }^{2}$ Department of Drug Regulatory Affairs, Poona College of Pharmacy, Bharati Vidyapeeth (Deemed to be University), Pune, \\ Maharashtra, INDIA.
}

\begin{abstract}
The present generation of students has information at their hands with the advances in technology. The conventional teaching in monologue manner, just delivering bookish information and dictation are ineffective to inculcate knowledge and confidence in them. Attendance is another major challenge for the current educational system. Assessment patterns have improved from 'marking' to 'continuous grading' systems. However, the questions in examinations merely evaluate the memorizing and writing skills of the students. There is limited scope for students to think in a scientific and logical manner. In addition, there is a need for teaching-learning beyond the classrooms in emergencies like the prevailing pandemic of Coronavirus Disease / COVID-19. The adoption of Information and Communication Technology (ICT) tools will not suffice all these requirements. Interactive teaching-learning would help to convert bookish information into life-long knowledge. Case-based problem-solving questions would create the need for thinking. The blending of skills and knowledge will inculcate value and confidence in students along with their university degrees. A pre-study perception survey was performed to understand the educational needs of students and expectations of parents and the pharma industry, followed by activities to promote interactive teaching-learning in a selected institute. The post-study feedback survey revealed interesting results, which will, boosts effective knowledge dissemination along with improved student attendance.
\end{abstract}

Key words: Interactive, Teaching, Learning, Thinking, Examination.

\section{INTRODUCTION}

Education is a key factor in the life of a human being that is essential for the overall progress of an individual as well as society. Education helps the individual to acquire knowledge, skills and experience during his journey of life. ${ }^{1}$ Teaching and learning process is not effective if it is monolog and monotonous; instead, it must be interactive and there has to be a dialogue between the teacher and the student. ${ }^{2}$ This will also help in the continuous evaluation and motivation of the students. Knowledge gain is not limited merely to the years of study, the number of books read or distinctions earned in academics; nor is success measured from the monetary achievements during the life span. However, peer group and societal pressures are pleased to value education in terms of grades/ marks, degree certificates and pay incomes. In order to cater to these demands, the education system pertains only towards the completion of the syllabus, academic requirement of attendance and evaluation just for the sake of an academic degree.

For generations together, it is evident that very few merit students become successful personalities whereas many backbenchers succeed to become role models for society. This emphasizes the deficiency of our
Submission Date: 24-11-2020; Revision Date: 19-05-2021: Accepted Date: 24-08-2021

DOI: 10.5530/ijper.55.3s.173 Correspondence: Dr. Atmaram P Pawar, Professor and Principal, Department of Pharmaceutics, Poona College of Pharmacy, Bharati Vidyapeeth (Deemed to be University), Pune411038, Maharashtra, INDIA. Phone: +91 20- 25461046, Email - p_atmaram@rediffmail.com

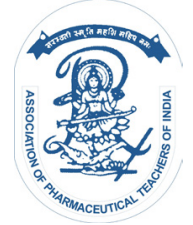

www.ijper.org 
education system and academic curriculum. Thus, there is a need for improving the gaps in the teaching-learning process. Failure to correlate syllabus completion with equivalent and efficient knowledge transfer and flawed similarity between information transfer and knowledge dissemination was the key loopholes of the teaching-learning process. Instead of physical attendance for academic success, more valuation needs to be attributed to the mental presence of students. ${ }^{3}$ It should be clearly noted that all types of assessments, as well as examinations, should not be limited to memory-based evaluation. However, teachers should promote intellectual thinking and develop logical reasoning in the students. Therefore, knowledge should inculcate wisdom and overall development for improving student achievements. Thus, interactive teaching is essential for effective knowledge dissemination, improved student comprehension as well as the persistent assessment of students.

An interactive, skill-based education along with a problemsolving approach should be implemented as good teaching-learning practices. This would promote students' attention and interest in teaching-learning which facilitates transforming bookish information into life-long knowledge. Interactive teaching-learning calls for active engagement from evaluators to set casebased questions in examinations. This will help to inculcate thinking abilities as well as would act as a blend of skills and knowledge to augment the value of the university degree.

The prime aim of this study was to enhance the effectiveness of interactive teaching-learning with the involvement of students for the successful transfer of 'information into knowledge' and 'marks into confidence' as a model of lifelong learning. This project was planned with the objectives to a) increase student's interest in studies through direct studentteacher interaction, b) inculcate logical thinking through interactive teaching and c) promote knowledge outcome by replacing memory-based examinations with case-based problem-solving studies.

\section{MATERIALS AND METHODS}

This project was designed with the main purpose to improve attendance and achieve effective knowledge delivery by promoting interactive teaching-learning. This work was dividied in 3 stages - perception survey, prototype study and feedback survey. The prototype study was designed based on outcomes of the perception survey. The post-study feedback survey helped to comprehend the successful transfer of information into knowledge' and 'marks into confidence' as a result of effective interactive teaching-learning and maximum involvement of students.

\section{Set up}

\section{Prototype study and survey}

The prototype study was designed based on the outcomes of the pre-study survey that included 440 student's participants, faculty, industrial professionals and parents. This prototype study was designed and implemented at Poona College of Pharmacy, Pune for a span of 106 days, starting from $1^{\text {st }}$ December 2019 to $15^{\text {th }}$ March 2020. The scope of feedback survey included undergraduate pharmacy students, interested faculty members teaching various subjects $(\mathrm{n}=16)$ and volunteered stakeholders such as parents and alumni $(n=390)$. The study was conducted under the Change Management Project of the UKIERI Leadership Development Programme 2019-20 organized by AICTE, New Delhi.

\section{Sources of data and information}

The apex pharmacy educational bodies in India such as AICTE, Pharmacy Council of India (PCI) and as a constituent unit of Bharati Vidyapeeth (Deemed to be University), Poona College of Pharmacy, Pune (as host institute) have laid down the minimum standard of $80 \%$ attendance to the students for both, theory as well as practical subjects. Erstwhile, attendance for theory and practical sessions was documented as offline manually. Under the present project, the prevalent procedures were modified and used as a source of data and information. Attendance records and percent attendance of the students was the quantitative, primary source. Drafting and publication of attendance policy was the qualitative resource. Student and teacher perception and feedback surveys constituted a qualitative, secondary source of information. The in-charge of academic monitoring and attendance committee along with class teachers and members of the students' council framed the attendance policy, which was implemented from $5^{\text {th }}$ September 2019. Excel formats were designed and used for ease of calculation and compilation of the class-wise attendance.

The Google form-based electronic questionnaire was framed as the most appropriate data collection tool for the conduct of the surveys. The literature assessment was inadequate in identifying the appropriate prevalidated questions apt to obtain the required data. So, a new questionnaire was subsequently developed for the perception survey on 'Effective knowledge delivery by improving attendance and promoting interactive teaching'. A brief post-study feedback survey based on 
Google questionnaire form was conducted between $13^{\text {th }}$ to $19^{\text {th }}$ March 2020 to obtain study-outcomes. The students' attendance for the current academic session was compared with that of the previous academic sessions to evaluate the change in average attendance.

In the second aspect of this study, ICT based techniques were introduced to promote interactive teaching-learning. The authors introduced the concept as well as the significance of interactive teaching to the students using PowerPoint presentations. This concept was incorporated in the academic policy and practiced during the setting and evaluation of question papers. These were qualitative input parameters. Comparative analysis of pre-study and post-study feedback surveys along with question papers of past and present examinations formed the quantitative, secondary sources.

These presentations were shared with the faculty members and students with the aim of promoting effective knowledge delivery, thus improving attendance. Additionally, the authors delivered invited talks on the concept of interactive teaching-learning at two national level AICTE sponsored FDP and at various state universities. Videos on interactive teaching-learning for effective knowledge delivery were circulated on YouTube as well as Facebook for a broader perspective. 'Policy for interactive teaching and case-based problemsolving examinations' was reframed based on the perception survey. The outcome of teaching orientation and the question papers was obtained through evaluating examination performance and post-study feedback survey. The post-study feedback survey involved a comparison between question papers of the previous session and that drawn post-project implementation, the performance of students in viva examinations and overall confidence. Qualitative and quantitative observations were correlated with the students' interest in attending classes, knowledge gain and outcomes.

In addition to these methods and policies, flexibility for its modifications during prototype study was maintained. Also, the student council and academic monitoring committees were involved in improving the acceptance of this project. Students and faculty with good participation were appreciated.

\section{RESULTS}

The participation of the pre-study survey included a total of 440 participants out of which $63 \%$ were students, $28.6 \%$ were faculty and $8.4 \%$ were industrial professionals and parents. The promotional events received an overwhelming response as shown in Figure 1 (A and $B$ ).

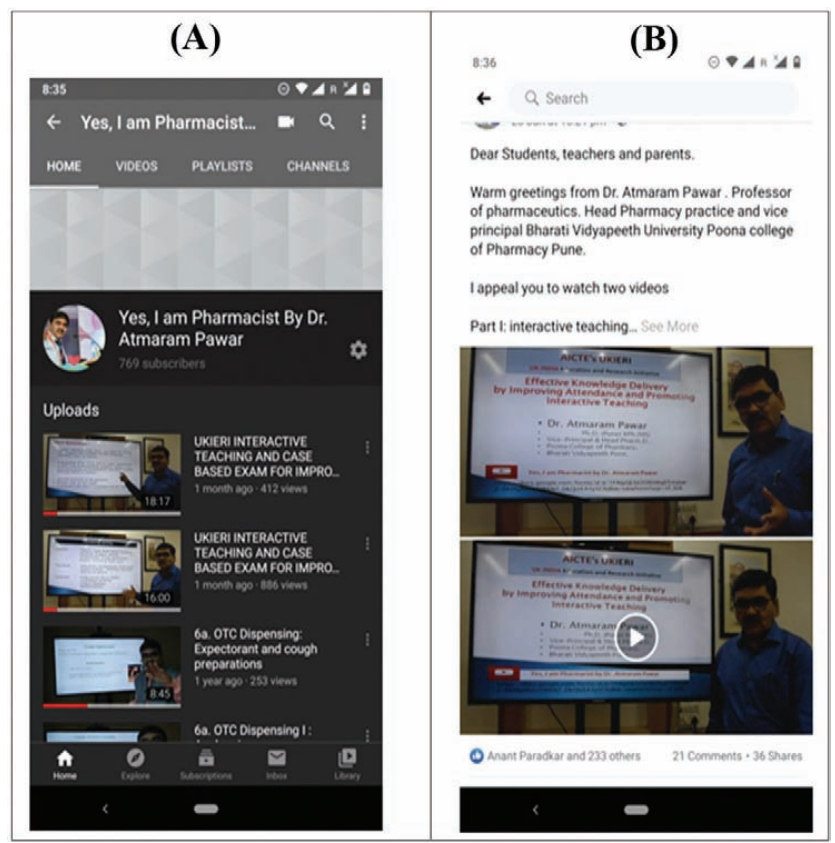

Figure 1: Responses from participants (A) 886 views on YouTube and $(B)$ more than 233 views, 21 comments and 36 shares on Facebook.

Preliminary changes in the erstwhile manual attendance system had streamlined the process of attendance recording and improving not only the presence but also interest of the students in attending the classes. From the $63 \%$ student participants in the pre-study perception survey, $95 \%$ of students belonged to the host institute.

\section{Students Attendance}

Figure 2 (A to D) demonstrates the survey outcomes for different parameters related to teaching techniques, evaluation of effective teaching-learning, the inclusion of case-based problem-solving questions as well as reasons for poor attendance in the class. As per the perception survey, about $90 \%$ of students attend the classes because it is a mandatory requirement. However, $40 \%$ of students found no benefit of attendance neither in passing the examinations nor for knowledge gain (Figure 2A).

Very positively, $79.7 \%$ of participants' perception suggested that interactive teaching and problem-solving based examinations could encourage attendance; more precisely $48.6 \%$ and $31.1 \%$ of them expected improvement in attendance of students by $50-75 \%$ and $75-100 \%$ respectively (Figure 3). The prototype study indicated enhanced average attendance for the classes understudies from $65 \%$ in the last academic session to $78 \%$ in the current academic session. The post-study feedback survey based on 192 responses also asserted 
(A) What do you think may be the reason for poor attendance?

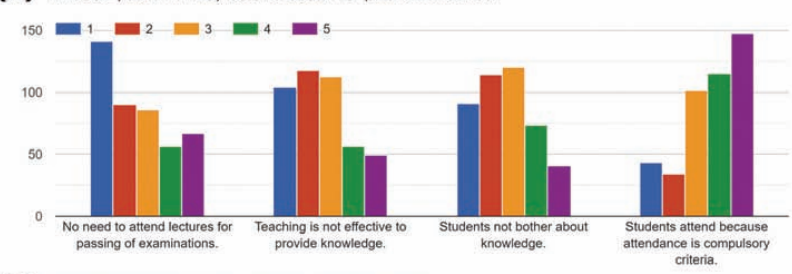

(B) Teaching can be made interesting by adopting the following ways -

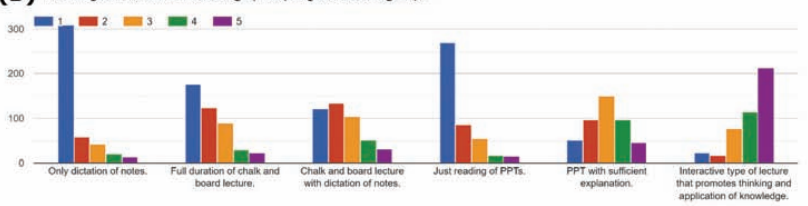

(C) What types of questions in exam are useful for evaluation of effective teaching-learning?

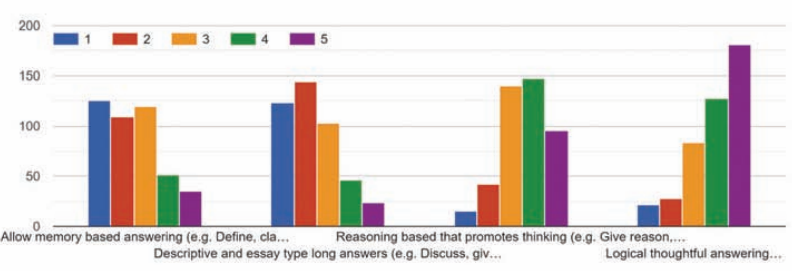

(D) What percent of marks should be allotted for case based problem solving questions in examinations:

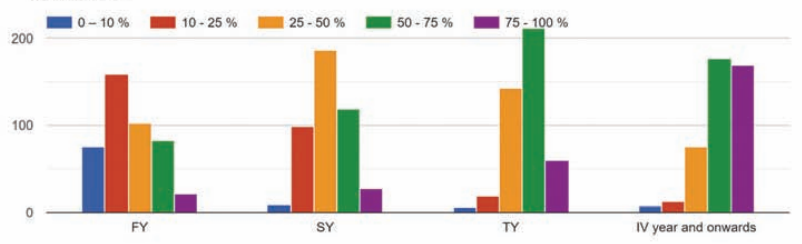

Figure 2: Survey outcomes for (A) Interesting teaching methodologies (B) Useful questions to evaluate effective teaching-learning (C) Class wise weightage for case-based problem-solving exam questions and (D) Reasons for poor attendance.

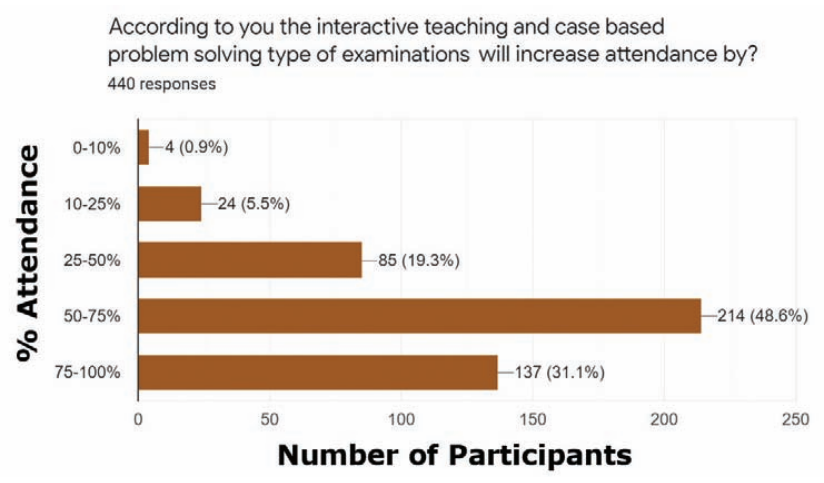

Figure 3: Perception of improved attendance due to interactive teaching.

the views expressed in the pre-study survey where $66 \%$ of respondents observed significant improvement in attendance due to the interactive teaching policy implementation (Figure 4A).

\section{Teaching- Learning and Evaluation}

As shown in Figure 2C, the regular evaluation system mainly based on memory-based, descriptive and essay
(A) The objectives of present students regarding education is to obtain -

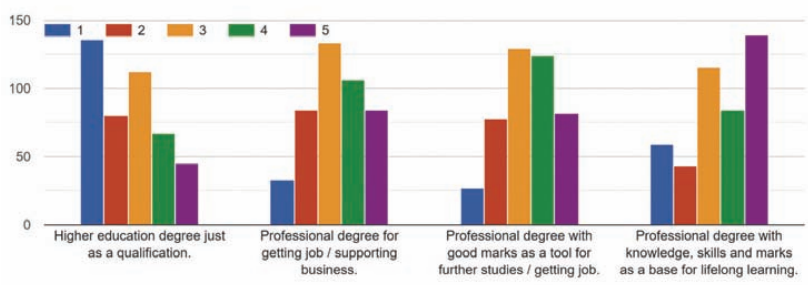

(B) How much percent of knowledge and skills are gained by students during their UG/PG studies at present?

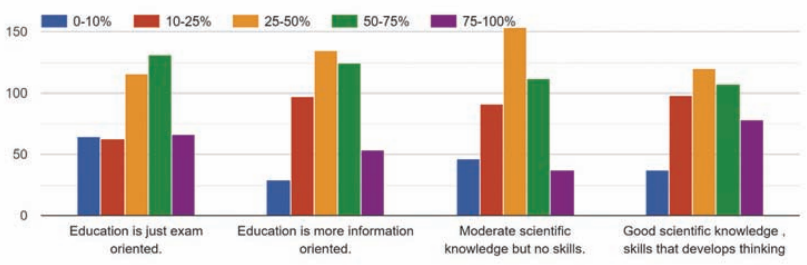

Figure 4: Survey outcomes of (A) Educational objectives of current students and (B) Percentage of knowledge gained by students during their undergraduate / UG and postgraduate / PG studies.

type of questions that rarely left scope for thinking. However, participants' opinion was the need for casebased problem-solving questions that would instigate thinking abilities in students. However, the students must be guided to think in a focused way and apt manner. Therefore, the proportion of case-based questions can be increased gradually with higher standards with $10-20 \%$ for first-year (FY) to $50-75 \%$ for the final year of the degree course (Figure 2D). As per the observations of the pre-study perception survey, $53.33 \%$ of subject teachers voluntarily opted for interactive teaching practices. During internal examinations, question papers of 14 subjects were included with problem-based questions accounting for $10-20 \%$ of the maximum marks. Similar practices were adopted in the other two national universities.

As per the perception study, an equal number of students wished to pursue higher education for fetching a good job, enrolling in a better institute and acquiring a professional degree with knowledge and skills (Figure 4A). Most of the participants believed that contemporary teaching provides moderate knowledge without skills or thinking opportunities. Current pedagogical methods suffice the exam requirements and fail to give sufficient knowledge gain to undergraduate and postgraduate students (Figure 4B). As per the opinion of more than $90 \%$ of participants, interactive teaching and problemsolving type examinations would help in effective knowledge delivery and skill development (Figure 5).

The post-study feedback survey outcomes are as shown in Figure 6. There was almost $100 \%$ participation in 


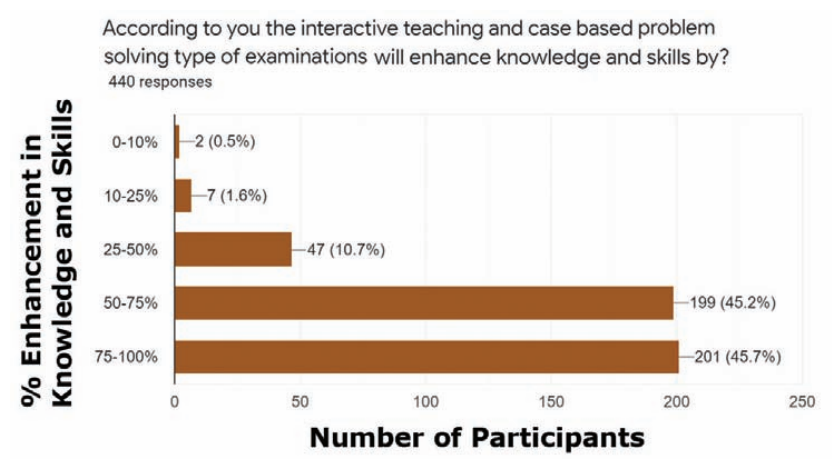

Figure 5: Perception of the enhancement of knowledge and skills due to interactive teaching.

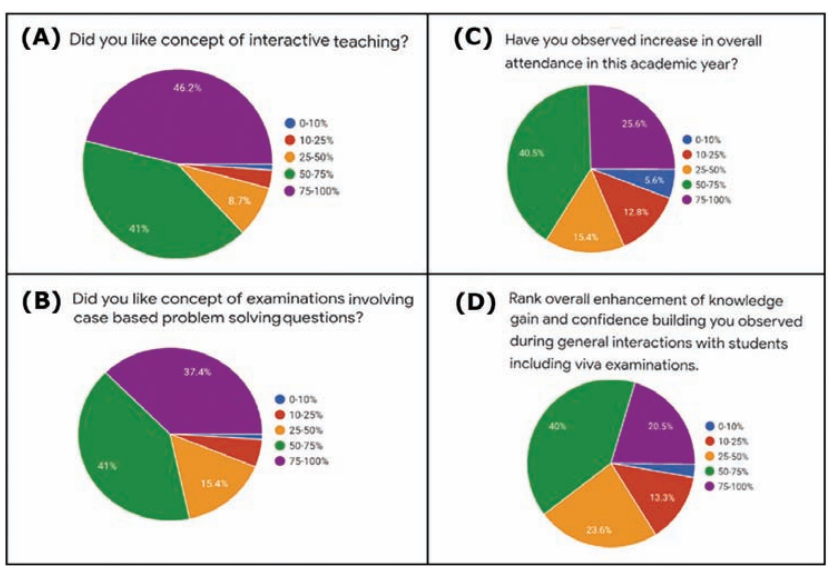

Figure 6: Outcomes of post-study feedback survey towards (A) Interactive teaching-learning concept (B) Case-based problem-solving questions (C) Improvement in attendance (D) Overall improvement in the knowledge and confidence of the students after the implementation of interactive teaching policy.

this perception survey with a maximum inclination towards the concept of interactive teaching (Figure 6A). Authors were able to convince $53.33 \%$ of faculty and $67.79 \%$ of students the importance of this interactive pedagogy by coaching and democratic ways. The concept of interactive teaching-learning has successfully experimented in 30 subjects of undergraduate courses. During the internal evaluation, $93.75 \%$ of case-based problemsolving questions were included in the examinations. More than $75 \%$ of students attempted these problemsolving questions as reflected in Figure 6B. Improvement in average attendance was observed from 65\% (the academic year 2018-2019) to 78\% (the academic year 2019-2020) (Figure 6C). About 65\% of participants felt twice the improvement in knowledge gain and confidence building of students as observed during their regular viva voce (Figure $6 \mathrm{D}$ ).

\section{DISCUSSION}

This project was designed and implemented with the help of Lewin's model of change and Kotter's 8 Step Change Model. Lewin's 3 step model of change comprises of unfreezing, changing followed by refreezing. This embrace creating the perception that a change is required (pre-study perception feedback), followed by the new, desired level of behavior (policy framing) and, lastly, refreezing the new behavior as the post-study feedback. ${ }^{4}$ The study was also, grounded on John Kotter's 8-step change model which included 8 sequential steps in the following manner:

1. Creating urgency (like prevailing pandemic outbreaks),

2. Forming a strong alliance (students, faculty, parents, professionals, academicians, stakeholders),

3. Create a vision for change (policy framing),

4. Communicating vision (pre-study perception survey),

5. Overcoming the obstacles (modifying strategies during implementation),

6. Generating short term appreciation (student and faculty appreciation),

7. Constructing on the changes (post-study feedback survey) and

8. Setting the changes (implementation during the lockdown period of Coronavirus Disease / COVID pandemic outbreak). ${ }^{5}$

As illustrated in Figure 1, overwhelming responses on various platforms such as YouTube, Facebook, FDP sessions and seminars to this interactive teachinglearning concept underlined the excellent acceptance by the faculty, students, parents and professionals. The pre-study and post-study questionnaires assessed the diverse responses ranging from participation, cognitive abilities and problem-solving potential. This project improved the relationship between teachers and students as depicted from the improved students' attendance and their participation in the survey (Figure 2A and 3). In accordance with the prevalent pedagogical theory, it was observed that the ICT tools proved to be an added teaching tool for setting the framework of student's learning and enabling the teaching of pharmaceutical topics to undergraduate students. ${ }^{6}$ Placing various apps and tools on cell phones and laptops enabled learning without distractions, which motivated students to participate more with a loner focus span. ${ }^{7,8}$ Implementing the interactive teaching-learning strategies helped in simplifying the concepts of students that they tend to misunderstand. Faculty involved in teaching undergraduate students were contented with the implementation of these strategies, which improved the classroom 
presence of students and their involvement in attempting the case-based problem-solving questions (Figure 6A to $6 \mathrm{C}$ ). Improved student's attendance enhanced their learning that in turn, encouraged their maximum participation.

Currently, education has become dynamic to adapt to changes in technology and societal needs. Students need knowledge, skills and techniques to address the problems (Figure 4A). Not only students but teachers also have to upgrade themselves with modern information, skills and techniques. ${ }^{9}$ This is possible only through discussions and interactions between teachers and students. Interactive teaching-learning builds good scientific knowledge, professional skills along with thinking abilities (Figure 4B and 5).

Examinations not only involve testing student's knowledge but also teaching effectiveness. ${ }^{10}$ Interactive-teaching improved student participation as well as faculty advancement. Incorporating case-based problem-solving questions in examinations benefited the students to learn beyond the bookish information and inculcate the work ethics of their respective professions. During, interactive teaching, faculty could provide students with real-life situations as case studies or questions. ${ }^{11}$ This helped students to apply the taught knowledge as well as develop interpersonal qualities and professional skills along with prospects to determine their career inclination. ${ }^{12}$ Implementation of interactive teaching tools helped in improving the knowledge and confidence of the students during their viva-voce sessions and group assignments. Enhanced knowledge and confidence of the students during their viva sessions and group assignments (Figure 6) showed that these strategies helped students to retain the concepts as well as stimulated deeper understanding. ${ }^{6}$ Also, it substantiated the team-based learning approach. ${ }^{13}$ The post-study survey revealed students' predilection for case-based problem-solving examinations with $62.1 \%$ of students attempting these questions in different subjects. The inclusion of similar questions during the continuous assessment will accustom students to the thinking and correlation approach with an improved percentage of students' predilection. ${ }^{14,15}$

The perception survey, actual study and feedback survey support the interactive teaching. As indicated in Figure $6 \mathrm{~A}$ to $6 \mathrm{D}$, it was depicted that the problem-solving exam is not the only alternative to currently used memory-based exams but also the best tool to improve the attendance of students. In addition, this study fulfills the objectives of enhancing students' interest in studies by providing them opportunities to think, build their confidence and gain knowledge.

\section{CONCLUSION}

Surveying the efficacy and applications of interactive teaching and case-based problem-solving examinations provided a means of internally evaluating the potential of teaching-learning strategies on the overall student participation and performance. The findings discussed here support previous studies that highlight the increase in students' attendance with enhanced knowledge gains. We plan to broaden this study for different types and levels of courses such as post-graduate students, other courses and disciplines to assess if these same strategies are useful and effective or else need alternative tools like flipped-classroom, team-based learning to address their individual course demands. Further, we have already planned to compile and publish the list of the tools and technologies with their potential of application in our upcoming publication. The compiled list of tools may prove useful for conducting different activities such as online interactive teaching-learning as well as online examination, assessment and evaluation.

\section{ACKNOWLEDGEMENT}

The authors are grateful to all Faculty, Alumni, Parents, Students and all stakeholders of Poona College of Pharmacy, Pune for participating in this survey and providing us their valuable response, opinions and suggestions.

\section{CONFLICT OF INTEREST}

The authors declare no conflicts of interest.

\section{Disclosure Statement}

This study is a part of the UKIERI Change Management Project 2019-20.

\section{ABBREVIATIONS USED}

AICTE: All India Council for Technical Education; FDP: Faculty Development Program; ICT: Information and Communication Technology; UKIERI: UKIndia Education and Research Initiative.

\section{REFERENCES}

1. Gibson $D$, Webb $M$, Ifenthaler $D$. Measurement challenges of interactive educational assessment. In: Sampson DG, Spector JM, Ifenthaler D, Isaías P, Sergis S, editors. Learning technologies for transforming large-scale teaching, learning and assessment. Switzerland AG. Springer International Publishing; 2019. p. 19-33. 
2. Yukhimenko AN, Mefodeva MA, Belyaeva A, Leonidovna Grigorieva L. Interactive teaching methods as means of stimulating reserves of student interaction. Int J Sci Study. 2017;5(6):58-62.

3. Saulnier BM, Landry JP, Longenecker HE, Wagner TA. From teaching to learning: learner-centered teaching and assessment in information systems education. J Inf Syst Educ. 2008;19(2):174.

4. Hartzell S. Lewin's 3-stage model of Change: unfreezing, changing and refreezing [internet] [cited Mar 29 2020]. Available from: https://study.com/ academy/lesson/lewins-3-stage-model-of-change-unfreezing-changingrefreezing.html.

5. Kotter J. Kotter's 8 step Model of Change [internet] [cited Mar 29 2020]. Available from: https://www.managementstudyguide.com/kotters-8-stepmodel-of-change.htm.

6. Curley LE, Wu Z, Svirskis D. Using technology in pharmacy education: pharmacy student performance and perspectives when visual AIDS are integrated into learning. Front Pharmacol. 2018;9(SEP):1062. doi: 10.3389/ fphar.2018.01062, PMID 30319411.

7. Abdel Meguid E, Collins M. Students' perceptions of lecturing approaches: traditional versus interactive teaching. Adv Med Educ Pract. 2017;8:229-41. doi: 10.2147/AMEP.S131851, PMID 28360541

8. Alahmar AT. The attitude of second year pharmacy students towards lectures, exams and e-learning. Int J Educ Pedagog Sci. 2018;12(3):360-4.

9. Kear K. Social presence in online learning communities [internet]. In:. Open University. p. 3-4; 2010. Proceedings of the 7th international conference on
Networked Learning 2010. Aalborg, Denmark Dirckinck-Holmfeld L, Hodgson V, Jones C, McConnell D, Ryberg T, editors [cited May 20 2020]. Available from: http://www.networkedlearningconference.org.uk/.

10. Nemec EC, Baker DM, Zhang D, Dintzner M. Development of valid and reliable tools for student evaluation of teaching. Curr Pharm Teach Learn. 2018;10(5):549-57. doi: 10.1016/j.cptl.2018.02.009, PMID 29986813.

11. Nedungadi P, Mulki K, Raman R. Improving educational outcomes and reducing absenteeism at remote villages with mobile technology and WhatsApp: findings from rural India. Educ Inf Technol. 2018;23(1):113-27. doi: 10.1007/s10639-017-9588-z.

12. Bullen K, Davison K, Hardisty J. Community pharmacy as an effective teaching and learning environment: student perspectives from a UK MPharm programme. Curr Pharm Teach Learn. 2019;11(9):902-8. doi: 10.1016/j. cptl.2019.05.007, PMID 31570127.

13. Mitroka JG, Harrington C, DellaVecchia MJ. A multiyear comparison of flipped- vs. lecture-based teaching on student success in a pharmaceutical science class. Curr Pharm Teach Learn. 2020;12(1):84-7. doi: 10.1016/j. cptl.2019.10.014, PMID 31843170.

14. Aburahma $\mathrm{MH}$, Mohamed $\mathrm{HM}$. Educational games as a teaching tool in pharmacy curriculum. Am J Pharm Educ. 2015;79(4):59. doi: 10.5688/ ajpe79459, PMID 26089568.

15. Chin C, Osborne J. Students' questions: a potential resource for teaching and learning science. Stud Sci Educ. 2008;44(1):1-39. doi: 10.1080/03057260701828101.

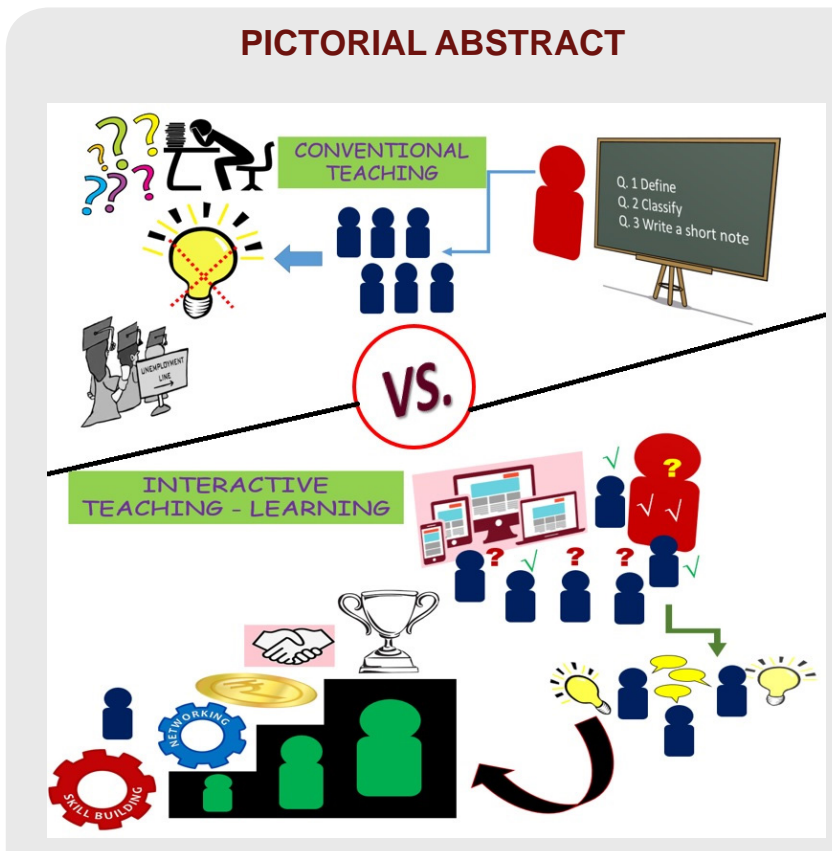

\section{SUMMARY}

Now a days, students can easily access the information with help of advanced technology. Conventional teaching methods are insignificant in terms of knowledge delivery as well as building confidence in them. Moreover, implementation of 'continuous grading' systems as well as the type of questions asked in examinations are focused only towards evaluating the memorizing and writing skills of students and have limited scope in improving the logical and scientific thinking ability of the students. Attendance is another major challenge for the current educational system. Further, the use of ICT tools, for effective online teaching-learning beyond the classrooms as well as in developing skills and knowledge is need of hour in current COVID19 pandemic. This will help to inculcate professional ethics, values and confidence in students along with their academic degrees. In the present research work, the Google form-based pre-study perception survey was conducted to understand the educational needs of students, faculty, expectations of parents and the pharmaceutical industry. Moreover, a brief post-study feedback survey was also conducted and the study-outcomes were compared with pre-study survey. The poststudy survey recorded the significant improvement in attendance, knowledge gain and confidence building of students with interactive teaching. Therefore, implementation of interactive teaching-learning practices would result in boosting of effective knowledge dissemination along with improved student attendance. 


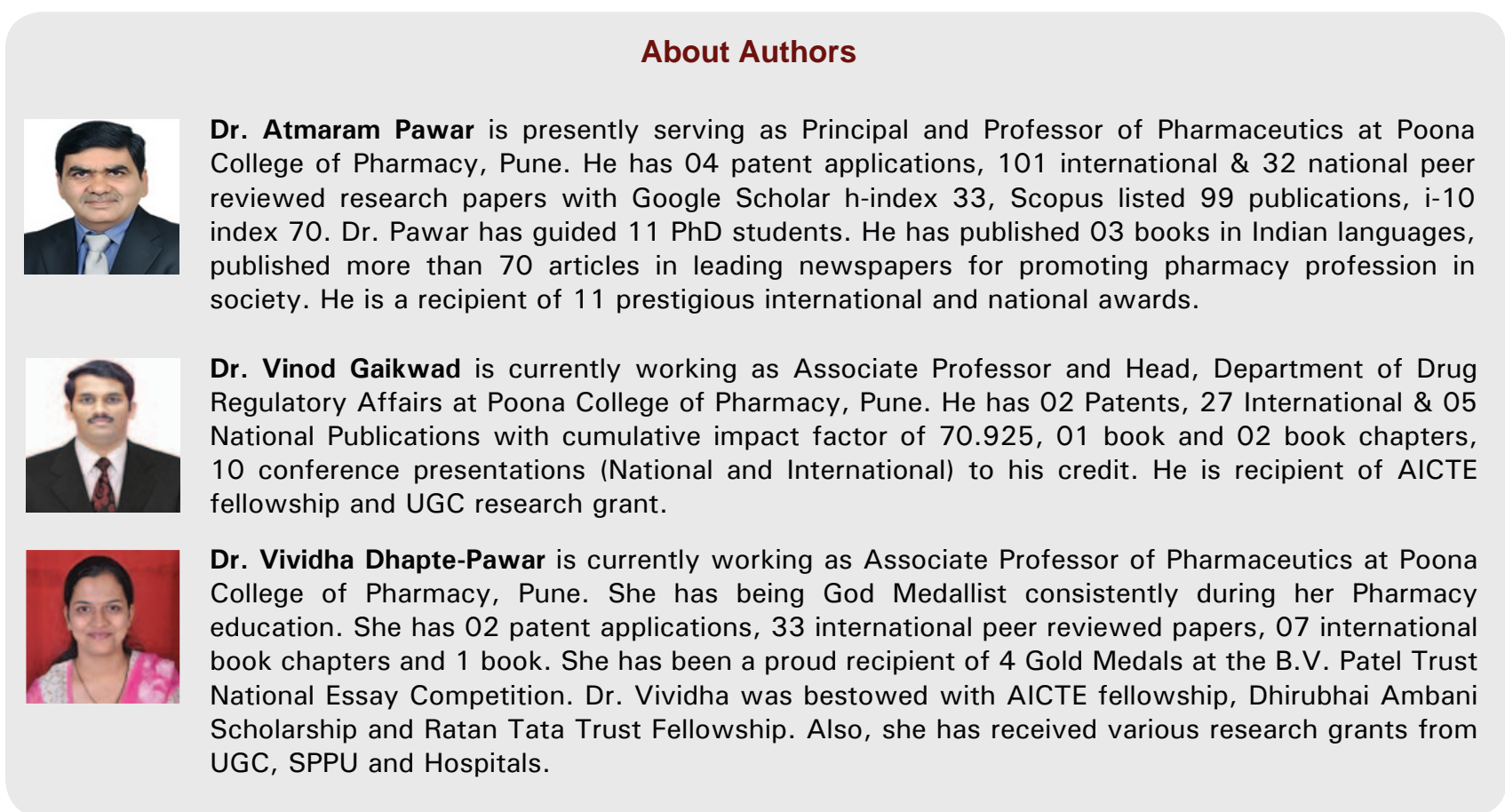

Cite this article: Pawar AP, Dhapte-Pawar VV, Gaikwad VL. Interactive Teaching in Higher Education for Effective Knowledge Dissemination and Improved Student Participation. Indian J of Pharmaceutical Education and Research. $2021 ; 55(3 s): s 664-s 671$. 